\title{
Do emergency physicians know the costs of medical care?
}

\author{
Grant Innes, MD;* Eric Grafstein, MD;* Jonathan McGrogan, BSc $\dagger$
}

\begin{abstract}
Objectives: To estimate the level of knowledge that Canadian emergency physicians have of the costs of common diagnostic tests and interventions in the emergency department (ED).

Methods: In a cross-sectional survey, 75 emergency physicians from 7 community and academic EDs were asked to estimate the cost of 60 of the most commonly ordered imaging modalities, laboratory tests and pharmaceuticals. Their estimates were compared to actual costs obtained from hospital finance departments. For each test or pharmaceutical, physician error was calculated as a percentage of the actual value, using the formula [(actual - estimated) / actual] $\times 100$. For each item, the proportion of responses that were underestimates, the proportion that were overestimates and the proportion that were accurate within $25 \%$ were reported.

Results: Mean error of the physicians' estimates was 40\% (95\% confidence interval [Cl], 35\%-45\%) for imaging studies, $153 \%(95 \% \mathrm{Cl}, 128 \%-178 \%)$ for lab investigations, and $218 \%(95 \% \mathrm{Cl}$, $179 \%-257 \%$ ) for pharmaceutical costs. Rates of underestimation vs. overestimation were $68 \%$ vs. $16 \%$ for imaging modalities, $23 \%$ vs. $56 \%$ for laboratory tests, and $21 \%$ vs. $64 \%$ for pharmaceuticals. Conclusions: Emergency physicians have a limited knowledge of the costs of the tests and interventions they use on a daily basis. They tend to overestimate lab and pharmaceutical costs but underestimate imaging costs. Cost-awareness programs for emergency physicians are most likely to be beneficial if they focus on imaging modalities.
\end{abstract}

\section{RÉSUMÉ}

Objectif : Évaluer le niveau de connaissance des urgentologues canadiens quant aux coûts des épreuves diagnostiques et des interventions courantes au département d'urgence (DU).

Méthodes : Lors d'une enquête transversale, on demanda à 75 urgentologues travaillant dans 7 DU communautaires et universitaires d'estimer le coût de 60 produits pharmaceutiques, techniques d'imagerie et épreuves de laboratoire les plus couramment demandés. Leurs estimations furent comparées aux coût réels obtenus des départements des finances des hôpitaux. Pour chaque épreuve ou produit pharmaceutique, l'erreur du médecin fut calculée sous forme de pourcentage de la valeur réelle, à l'aide de la formule suivante : [(réel - estimé) / réel] $\times 100$. Pour chaque item, on rapporta la proportion de réponses qui étaient des sous-estimations, la proportion de celles qui étaient des surestimations et la proportion de réponses exactes à $25 \%$ près.

Résultats : L'erreur moyenne pour les estimations des médecins était de $40 \%$ (IC à $95 \%, 35 \%$ $45 \%$ ) pour les études d'imagerie, de $153 \%$ (IC à $95 \%, 128 \%$-178 \%) pour les épreuves de laboratoire et de $218 \%$ (IC à $95 \%, 179 \%-257 \%$ ) pour les coûts pharmaceutiques. Les taux de sousestimation par rapport à la surestimation étaient de $68 \%$ vs $16 \%$ pour les techniques d'imagerie, de $23 \%$ vs $56 \%$ pour les épreuves de laboratoire et de $21 \%$ vs $64 \%$ pour les produits pharmaceutiques. Conclusions : Les urgentologues ont une connaissance limitée des coûts des épreuves et des interventions qu'ils utilisent quotidiennement. Ils ont tendance à surestimer les coûts des épreuves de laboratoire et des produits pharmaceutiques mais à sous-estimer les coûts de l'imagerie. Les programmes de sensibilisation aux coûts destinés aux urgentologues devraient se concentrer sur les techniques d'imagerie.

Key words: emergency department, health economics, utilization, cost, cost-effectiveness 


\section{Introduction}

In 1990, Canadians made over 15 million visits to hospital emergency departments (EDs). ${ }^{1}$ At an average cost of $\$ 50$ per visit, total cost to the health care system was approximately $\$ 900,000,000 .^{2,3} \mathrm{ED}$ care is perceived as expensive and ED costs are viewed as a threat to the health care system. ${ }^{4-6}$

In recent years, an aging population, advancing technology, rising expectations and heavy utilization by patients and doctors have driven health care costs up. At the same time, federal cuts to Canada Health and Social Transfers? have led to budget crises, hospital bed closures, overcrowding, treatment delays and increasing emphasis on costeffective medicine.

Cost-reduction strategies focus on reducing ED utilization by patients ${ }^{5,89}$ and reducing resource utilization by physicians. Williams $\mathrm{s}^{10,11}$ determined that diverting patients from EDs will not lead to meaningful health care savings; therefore future cost-reduction strategies should focus on modifying physician utilization - most likely through the use of decision rules, rationing strategies, audit and feedback, and educational programs. ${ }^{12-22}$

Physicians admit patients to hospitals, order tests, perform procedures and prescribe medications. These actions account for a large proportion of health care costs, ${ }^{20,23}$ and it seems reasonable that physicians should have some awareness of the expenses they generate. Increasing physician cost awareness is a common strategy, ${ }^{15,16,19-21}$ but if costawareness programs are to be effective, the following conditions should exist: 1) physicians must have poor baseline cost awareness and should generally underestimate costs (if they overestimate costs, then greater cost awareness may increase utilization); 2) improved cost awareness should lead to reduced utilization, and this effect should persist beyond the intervention period; 3) decreased utilization must not lead to a worsening of patient outcomes.

Since many ED tests do not substantially alter patient management or outcome ${ }^{24,25}$ it is possible that targeted costawareness strategies may reduce utilization and decrease ED costs without negatively impacting patient outcomes. Assessing physician cost awareness is the first step in this process. ${ }^{23,26-31}$ No previous studies have looked at medical cost awareness among Canadian emergency physicians (EPs).

The study objectives were to determine the actual costs of common ED tests and interventions, to estimate EPs' knowledge of these costs and to determine whether EPs generally underestimate specific costs or cost groups. The hypothesis was that most physicians do not know (within 25\%) the costs of tests and interventions they use on a daily basis and that they routinely underestimate these costs.

\section{Methods}

\section{Study design}

In this cross-sectional survey, EPs from 7 hospital emergency departments were asked to estimate the costs of 60 of the most frequently ordered imaging modalities, laboratory tests and pharmaceuticals in the ED. The study did not involve human experimentation and was considered exempt from review by the university's research ethics committee.

\section{Population and setting}

The EDs of 7 hospitals in the Greater Vancouver area were chosen to participate, based on geographic proximity and staffing by full-time emergency physicians. The hospitals are a mix of urban and suburban centres, with annual volumes that range from 20,000 to 65,000 . Four of the 7 are teaching hospitals, and all survey responders were full-time EPs.

\section{Survey instrument}

Using hospital finance department data, a list was compiled of the 22 diagnostic imaging tests, 18 laboratory tests and 20 pharmaceuticals that contribute the greatest to total ED costs, based on both unit cost and frequency of use. A survey was developed, which asked respondents to estimate the true hospital cost (not charge) for each item. Respondents were instructed to consider only the cost of performing the test (including technician time) and not to include costs associated with physician interpretation (e.g., radiologist fees). The survey was pilot tested on several EPs and modified to ensure clarity.

To enhance response rate and reliability, all surveys were presented by one of the investigators (J.M.) at ED departmental meetings in a "face-to-face" fashion. Respondents were not told in advance about the specific nature of the questions and did not have access to reference materials.

\section{Actual costs}

The finance department of each participating hospital was asked to provide actual costs for the survey items; however, only 2 hospitals were able to provide ED cost data. Actual costs from both hospitals (A and B) and mean costs for the 2 hospitals are presented. For study purposes, the "actual" (reference standard) cost of an item was defined as the range between the costs provided by the 2 hospitals. Costs are reported in 1997 Canadian dollars. When a physician's estimate was below both hospital costs, it was considered "low." When it was above both hospital's costs, it was considered "high." If the EP estimate fell between the 2 hospitals' costs, it was considered exactly correct. Median EP cost estimate and range was determined for each item. 


\section{Estimation error}

For each item, the proportion of low, correct and high estimates was reported. EP estimation error was determined by subtracting the respondent's estimate for a given item from the closest corresponding hospital cost, using the formula:

$$
[(\text { actual }- \text { estimated }) / \text { actual }] \times 100
$$

Mean error for each item and category (imaging, laboratory and pharmaceutical) was calculated, as was the proportion of physicians who estimated within $25 \%$ of the closest hospital value.

\section{Results}

Seventy-five full-time ED physicians were approached; 24 from community hospitals and 51 from academic centres. All 75 agreed to participate in the study. The participants provided 4,495 cost estimates for 60 items. Five physicians failed to estimate the cost of octreotide, but apart from this there were no "missing" data.
Tables 1 to 3 show actual costs, EP estimates (mean and range) and EP estimation error for the imaging, laboratory and pharmaceutical items surveyed. Mean error of the physicians' estimates was $40 \%$ (95\% CI, 35\%-45\%) for imaging studies, $153 \%$ (95\% CI, 128\%-178\%) for lab tests and $218 \%(95 \% \mathrm{CI}, 179 \%-257 \%)$ for pharmaceutical costs. Physician estimates fell within $25 \%$ of the closest "actual" hospital cost $35 \%$ of the time for imaging modalities, $32 \%$ of the time for lab tests and $23 \%$ of the time for pharmaceuticals. Figures 1 to 3 show the proportion of low, correct and high EP estimates for each item. Rates of underestimation vs. overestimation were $68 \%$ vs. $16 \%$ for imaging modalities, $23 \%$ vs. $56 \%$ for laboratory tests and $21 \%$ vs. $64 \%$ for pharmaceuticals.

\section{Discussion}

Previous studies indicate that physicians have poor medical care cost awareness. ${ }^{15-31}$ The current study suggests that Canadian EPs also have limited knowledge of the costs of the tests and treatments they use on a daily basis. This rela-

Table 1. Actual and estimated costs for diagnostic imaging modalities

\begin{tabular}{|c|c|c|c|c|c|c|c|}
\hline \multirow[b]{2}{*}{ Imaging modality } & \multicolumn{3}{|c|}{ Actual item cost, $\$$} & \multicolumn{2}{|c|}{$\begin{array}{c}\text { EP estimates, } \$ \\
n=75\end{array}$} & \multirow{2}{*}{$\begin{array}{c}\text { EP \% error } \\
\text { mean (and SD) }\end{array}$} & \multirow{2}{*}{$\begin{array}{l}\text { No. (and } \%) \\
<25 \% \text { error }\end{array}$} \\
\hline & Hospital A & Hospital B & Mean & Median & Range & & \\
\hline \multicolumn{8}{|l|}{$\subset T$} \\
\hline Body & 249.50 & 423.67 & 336.59 & 375 & $55-2000$ & $42(63)$ & $49(65)$ \\
\hline Head & 115.78 & 133.88 & 124.83 & 250 & $30-800$ & $97(94)$ & $16(21)$ \\
\hline IVP & 142.23 & 205.23 & 173.73 & 100 & $30-300$ & $34(22)$ & $26(35)$ \\
\hline Perfusion scan, lung & 171.50 & 187.62 & 179.56 & 125 & $20-400$ & $44(28)$ & $19(25)$ \\
\hline Ventilation scan, lung & 145.50 & 180.34 & 162.92 & 100 & $25-400$ & $47(28)$ & $14(19)$ \\
\hline Ultrasound, abdomen & 88.25 & 153.71 & 120.98 & 80 & $10-300$ & $25(22)$ & $49(65)$ \\
\hline Doppler, leg & 59.89 & 69.49 & 64.69 & 75 & $30-300$ & $39(52)$ & $37(49)$ \\
\hline Ultrasound, pelvis & 82.90 & 127.27 & 105.09 & 80 & $25-300$ & $26(22)$ & $50(67)$ \\
\hline Flat plate, abdomen & 79.79 & 72.97 & 76.38 & 45 & $15-125$ & $41(24)$ & $15(20)$ \\
\hline \multicolumn{8}{|l|}{ X-rays } \\
\hline Ankle & 70.42 & 44.12 & 57.27 & 25 & $6-100$ & $39(22)$ & $23(31)$ \\
\hline C-spine & 102.69 & 73.19 & 87.94 & 40 & $15-175$ & $43(25)$ & $18(24)$ \\
\hline Chest & 68.18 & 51.07 & 59.63 & 30 & $10-125$ & $40(26)$ & $27(36)$ \\
\hline Clavicle & 60.92 & 41.34 & 51.13 & 25 & $5-75$ & $42(22)$ & $16(21)$ \\
\hline Face & 99.56 & 62.84 & 81.20 & 35 & $15-150$ & $40(23)$ & $28(37)$ \\
\hline Femur & 79.00 & 53.23 & 66.12 & 30 & $10-125$ & $39(27)$ & $29(39)$ \\
\hline Foot & 70.56 & 44.43 & 57.50 & 25 & $10-125$ & $41(23)$ & $23(31)$ \\
\hline Knee & 75.79 & 44.89 & 60.34 & 25 & $10-100$ & $39(22)$ & $24(32)$ \\
\hline Lumbar spine & 86.50 & 67.76 & 77.13 & 40 & $10-150$ & $44(24)$ & $16(21)$ \\
\hline Pelvis & 85.17 & 50.10 & 67.64 & 30 & $10-125$ & $37(25)$ & $27(36)$ \\
\hline Rib & 63.13 & 58.21 & 60.67 & 30 & $10-125$ & $44(25)$ & $24(32)$ \\
\hline Shoulder & 80.57 & 63.31 & 71.94 & 30 & $10-125$ & $47(23)$ & $22(29)$ \\
\hline Wrist & 69.15 & 43.64 & 56.40 & 25 & $10-100$ & $40(21)$ & $22(29)$ \\
\hline Mean & & & & & & 40 & $26(35)$ \\
\hline
\end{tabular}


Table 2. Actual and estimated costs for laboratory tests

\begin{tabular}{|c|c|c|c|c|c|c|c|}
\hline \multirow[b]{2}{*}{ Laboratory test } & \multicolumn{3}{|c|}{ Actual test cost, $\$$} & \multicolumn{2}{|c|}{$\begin{array}{c}\text { EP estimates, } \$ \\
n=75\end{array}$} & \multirow{2}{*}{$\begin{array}{c}\text { EP \% error } \\
\text { mean (and SD) }\end{array}$} & \multirow{2}{*}{$\begin{array}{l}\text { No. (and } \% \text { ) } \\
<25 \% \text { error }\end{array}$} \\
\hline & Hospital A & Hospital B & Mean & Median & Range & & \\
\hline Acetaminophen & 16.08 & 10.82 & 13.45 & 20 & $2-150$ & 99 (131) & $28(37)$ \\
\hline Arterial blood gas level & 8.91 & 19.03 & 13.97 & 20 & $3-100$ & $57(70)$ & $34(45)$ \\
\hline Digoxin level & 20.83 & 10.01 & 15.42 & 30 & $1-125$ & 77 (94) & $26(35)$ \\
\hline Ethanol level & 17.08 & 8.42 & 12.75 & 20 & $1-100$ & $69(95)$ & $39(52)$ \\
\hline Serum lactate & 10.20 & 7.65 & 8.93 & 20 & $1-150$ & $210(265)$ & $15(20)$ \\
\hline Serum osmolality & 23.80 & 29.52 & 26.66 & 20 & $1-100$ & $47(45)$ & $31(41)$ \\
\hline Chemistry $1 *$ & 4.14 & 5.70 & 4.92 & 15 & $1-200$ & $307(548)$ & $14(19)$ \\
\hline Chemistry $2 t$ & 4.41 & 5.95 & 5.18 & 20 & $2-250$ & $421(670)$ & $14(19)$ \\
\hline Chemistry $3 \ddagger$ & 4.41 & 5.77 & 5.09 & 20 & $3-275$ & $457(697)$ & $12(16)$ \\
\hline Chemistry $4 \S$ & 5.03 & 6.27 & 5.65 & 20 & $1-300$ & $445(671)$ & $8(11)$ \\
\hline Salicylate level & 16.08 & 6.58 & 11.33 & 20 & $3-75$ & $76(84)$ & $27(36)$ \\
\hline Urine dip & 0.29 & 4.98 & 2.64 & 5 & $0.20-30$ & $85(96)$ & $19(25)$ \\
\hline Urine test for pregnancy & 4.40 & 26.08 & 15.24 & 10 & $0.75-50$ & $43(23)$ & $27(36)$ \\
\hline Blood culture & 46.40 & 51.26 & 48.83 & 35 & $10-150$ & $47(37)$ & $24(32)$ \\
\hline Coagulation profile & 10.34 & 18.11 & 14.23 & 25 & $3-150$ & $93(130)$ & $32(43)$ \\
\hline Electrocardiogram & 25.48 & 49.34 & 37.41 & 20 & $2-150$ & $35(33)$ & $39(52)$ \\
\hline Hematology profile & 13.22 & 17.21 & 15.22 & 15 & $2-150$ & $72(124)$ & $31(41)$ \\
\hline Urine micro exam & 7.56 & 9.56 & 8.56 & 15 & $2-75$ & $109(131)$ & $17(23)$ \\
\hline Mean & & & & & & 153 & $24(32)$ \\
\hline
\end{tabular}

Table 3. Actual and estimated costs for pharmaceuticals tests

\begin{tabular}{|c|c|c|c|c|c|c|c|}
\hline \multirow[b]{2}{*}{ Pharmaceutical, dose } & \multicolumn{3}{|c|}{ Actual pharmaceutical cost, $\$$} & \multicolumn{2}{|c|}{$\begin{array}{c}\text { EP estimates, } \$ \\
n=75\end{array}$} & \multirow{2}{*}{$\begin{array}{c}\text { EP \% error } \\
\text { mean (and SD) }\end{array}$} & \multirow{2}{*}{$\begin{array}{l}\text { No. (and \% } \\
<25 \% \text { erro }\end{array}$} \\
\hline & Hospital A & Hospital B & Mean & Median & Range & & \\
\hline Cefazolin, $1 \mathrm{~g}$ IV & 1.74 & 3.53 & 2.64 & 15 & $2-100$ & $590(655)$ & $4(5)$ \\
\hline Cefuroxime, $750 \mathrm{mg} \mathrm{IV}$ & 6.02 & 8.08 & 7.05 & 30 & $3-100$ & $377(316)$ & $8(11)$ \\
\hline Charcoal, $50 \mathrm{~g}$ po & 5.25 & 8.33 & 6.79 & 10 & $0.50-60$ & $71(121)$ & $43(57)$ \\
\hline Clindamycin, 300 mg & 2.18 & 3.83 & 3.01 & 20 & $2-110$ & $722(724)$ & $3(4)$ \\
\hline Furosemide, $40 \mathrm{mg}$ IV & 0.40 & 2.27 & 1.34 & 5 & $0.20-50$ & $224(386)$ & $10(13)$ \\
\hline Gentamicin, $80 \mathrm{mg}$ IV & 2.31 & 3.28 & 2.80 & 8 & $0.30-50$ & $297(353)$ & $11(15)$ \\
\hline Hyoscine, $20 \mathrm{mg}$ IV & 3.80 & 5.90 & 4.85 & 10 & $0.50-50$ & $142(174)$ & $22(29)$ \\
\hline Lidocaine $1 \%, 5 \mathrm{~mL}$ & 0.14 & 3.26 & 1.70 & 3 & $0.05-50$ & $134(214)$ & $11(15)$ \\
\hline Lidocaine gel $2 \%, 10 \mathrm{~mL}$ & 2.61 & 4.92 & 3.77 & 5 & $0.30-25$ & $69(100)$ & $41(55)$ \\
\hline Midazolam, 2 mg IV & 1.49 & 5.41 & 3.45 & 10 & $1-100$ & $210(273)$ & $13(17)$ \\
\hline Naloxone, $0.4 \mathrm{mg}$ IV & 3.27 & 6.97 & 5.12 & 10 & $0.50-60$ & $145(166)$ & $7(9)$ \\
\hline Salbutamol, $2.5 \mathrm{mg}$ & 0.62 & 2.43 & 1.53 & 5 & $0.40-50$ & $294(438)$ & $21(28)$ \\
\hline Tetracaine, $1 \mathrm{~mL}$ & 1.35 & 3.43 & 2.39 & 2 & $0.20-50$ & $96(175)$ & $3(4)$ \\
\hline Octreotide, $0.1 \mathrm{mg} \mathrm{IV*}$ & 8.95 & 11.36 & 10.16 & 50 & $5-300$ & $491(487)$ & $2(3)$ \\
\hline Verapamil, 5 mg IV & 7.61 & 7.70 & 7.66 & 10 & $1-50$ & $126(142)$ & $4(5)$ \\
\hline Flumazenil, $0.3 \mathrm{mg} \mathrm{IV}$ & 22.58 & 29.17 & 25.88 & 30 & $3-200$ & $66(100)$ & $28(37)$ \\
\hline Ceftriaxone, $1 \mathrm{~g} \mathrm{IV}$ & 33.98 & 35.93 & 34.96 & 60 & $10-250$ & $116(147)$ & $19(25)$ \\
\hline Adenosine, $6 \mathrm{mg}$ & 31.64 & 32.93 & 32.29 & 40 & $12-250$ & $92(134)$ & $31(41)$ \\
\hline Streptokinase, $1.5 \mathrm{Mu}$ & 369.80 & 382.10 & 375.95 & 300 & $15-1500$ & $63(63)$ & $18(24)$ \\
\hline Alteplase, $100 \mathrm{mg}$ & 2089.00 & 2704.00 & 2397.00 & 2000 & $30-3600$ & $27(28)$ & $46(61)$ \\
\hline Mean & & & & & & 218 & $17(23)$ \\
\hline
\end{tabular}


tive ignorance is probably born in medical school, where health economics is underemphasized, and it is nurtured in residency training, where physicians learn the liberal application of advanced tests and treatments but seldom concern themselves with cost. ${ }^{26}$ Physicians are rarely told about the expenses they generate, and costs are excluded from industry advertising aimed at them. Third parties cover most patient bills, so ability to pay is rarely an issue. In addition, many physicians shun the concept of economic accountability and equate "cost-effectiveness" with poor medical ethics. ${ }^{16,30}$ These experiences and attitudes translate into a general disregard for the cost of the care delivered..$^{30}$

The primary goal of cost-effectiveness is not to reduce costs by limiting utilization, but to achieve maximum health benefit with the funds available. In these days of health care cutbacks, when the limit of available funding is reached and physicians can no longer provide timely care to all those who need it, every dollar spent unnecessarily is a dollar taken from a patient in need. If this is the case, then it is both ethical and important to spend health care dollars in a cost-effective fashion. ${ }^{30}$ However, without an awareness of medical care costs, physicians may find it difficult to practise cost-effectively.

Previous research shows that perceived cost influences utilization, ${ }^{15,16,20,22,26,32,33}$ and that physicians who underestimate costs order more diagnostic tests than those who estimate accurately or overestimate. ${ }^{22}$ Several investigators have shown that cost-awareness programs reduce utilization and expenditure. . $516,26,32-34$ This suggests that cost awareness may be a modifiable determinant in utilization behaviour. The current study was performed to help determine the need for cost-awareness education and to target where such efforts might be most beneficial.

This study confirmed the authors' hypothesis: that, overall, EPs at the study hospitals had a limited knowledge of common ED costs. Tables 1 to 3 show that EPs estimated within $25 \%$ of the actual range only $30 \%$ of the time. The largest relative estimation error $($ mean $=218 \%$ ) occurred

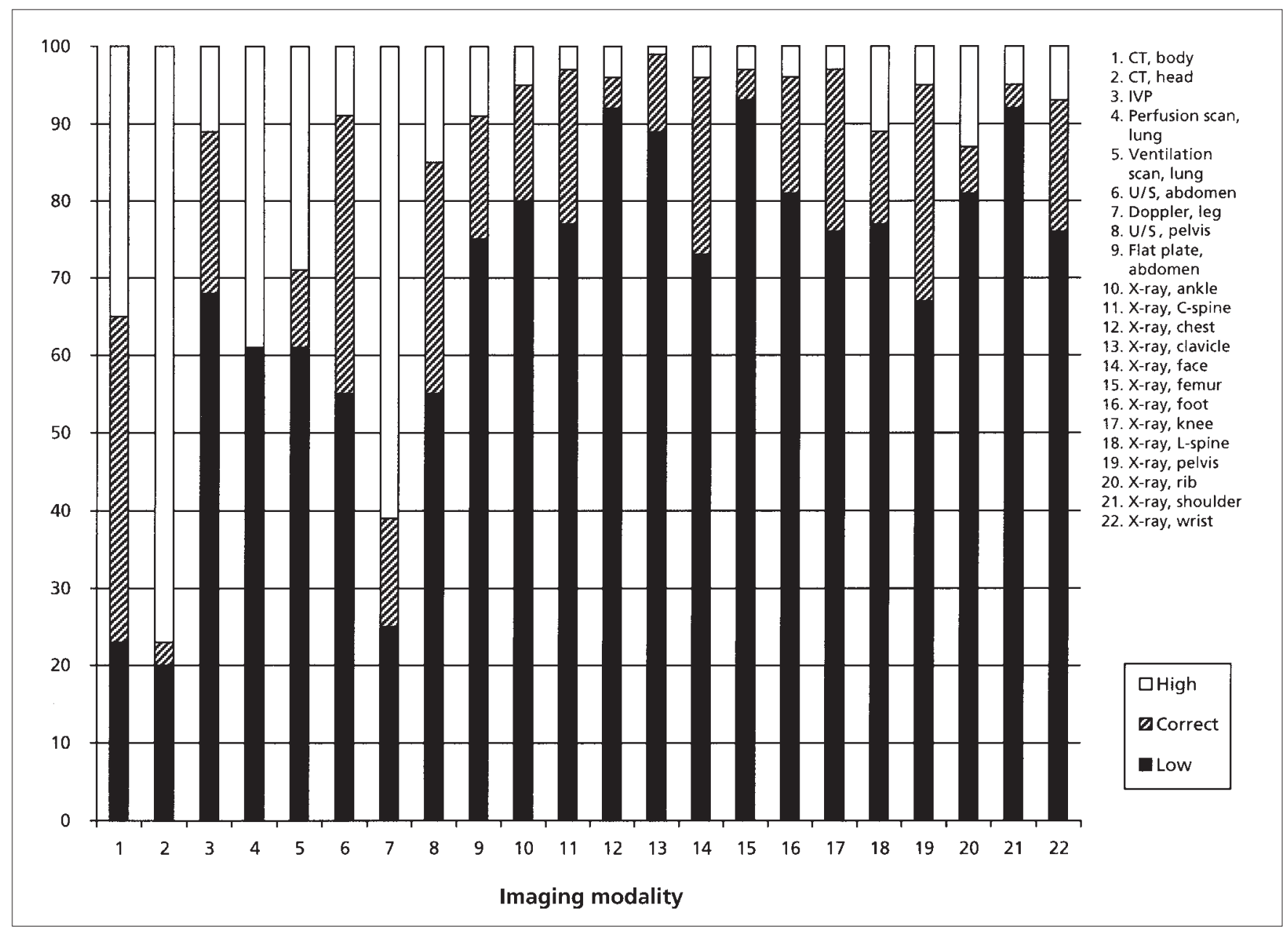

Fig. 1. Proportion of low, correct and high estimates for imaging modalities, $\%$. IVP = intravenous pyelogram; U/S = ultrasonography. 
with pharmaceutical agents and the smallest (mean $=40 \%)$ with imaging modalities. The data also show that the physicians tended to overestimate the cost of inexpensive items and underestimate the cost of expensive items.

Our belief is that cost-awareness programs are most likely to reduce unnecessary utilization when physicians underestimate costs. ${ }^{22}$ Of interest, we found that the EPs underestimated only $21 \%$ of pharmaceuticals and $23 \%$ of laboratory tests, suggesting that increasing physician cost awareness for these items is less likely to reduce utilization. Conversely, physicians underestimated imaging costs $68 \%$ of the time and plain radiographs $81 \%$ of the time. This, along with the fact that imaging modalities carry a higher unit cost than drugs and lab tests, suggests that ED costawareness programs are most likely to be effective if they are aimed at x-ray utilization.

One of the study's most interesting findings was that hospitals' finance departments also had a poor knowledge of medical care costs. Of the 7 hospitals surveyed, only 2 could provide ED cost data, and many of the "actual" costs differed substantially between hospitals. This is not a study flaw; it merely points out the disconcerting fact that, for hospital-based tests and imaging modalities, there is no such thing as an "actual cost."

Costs can be divided into "fixed" costs (e.g., equipment, maintenance of equipment, clerical staff, worker benefits, proportional hospital maintenance, heating and utilities) and variable costs (e.g., reagents, supplies, test kits, film and radiologist fees). Many costs, like reagents and supplies, are volume dependent and therefore vary from hospital to hospital. To complicate matters, some costs, like technician salaries, can be considered both fixed and variable. For example, if an ED reduced x-ray utilization by $5 \%$, this would not reduce technician salaries, since the same number of technicians would still be required. However, reducing utilization by $20 \%$ would reduce technician salaries if it allowed the hospital to hire one less technician. In hospitals with only one technician on duty at night, reducing night $\mathrm{x}$-rays by $50 \%$ would not reduce technician costs, since the technician would still be required to perform urgent studies.

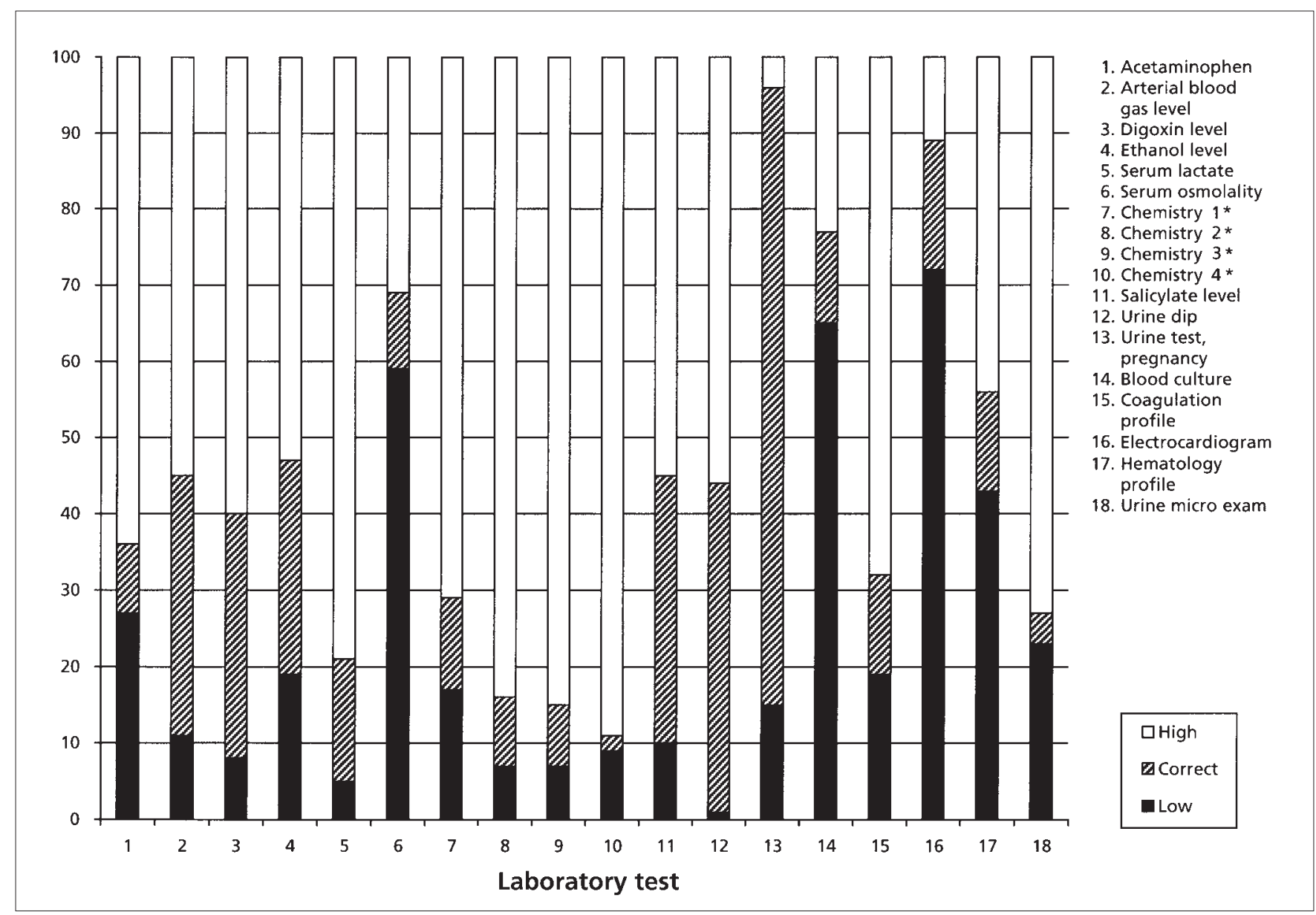

Fig. 2. Proportion of low, correct and high estimates for laboratory tests, $\%$. *Refer to Table 2 for description. 
Conversely, avoiding one CT scan (and the associated overtime technician callback) every other night would reduce costs substantially.

For all these reasons, "actual" unit costs do vary from hospital to hospital, depending on the equipment, the level and pattern of technician staffing, employee contracts, the volume of tests performed and the nature of supplier contracts. Some of the "actual cost" variability seen in this study (e.g., body CT) also reflects different accounting practices, cost averaging and cost shifting within hospitals.

Most previous studies avoid cost uncertainty by reporting hospital charges rather than costs; however, while charges are easier to measure, they incorporate institutional profit margins and are less reflective of the resources expended performing the test, hence less valid. This is especially true in the "not-for-profit" Canadian system.

Given the uncertainty surrounding "actual" costs, some might criticize the ability of this study to assess physician cost awareness. To balance this uncertainty and give the physicians the benefit of the doubt, the range between hospital values was considered as correct, and estimates within $25 \%$ of the upper and lower values were accepted as “good knowledge." Previous investigators have used similar methods. Skipper and colleagues defined cost estimates within $25 \%$ of a single actual value as "good knowledge" and found that $45 \%$ of attending physicians achieved this level of precision. ${ }^{29}$ Other researchers ${ }^{22,26,28,35-37}$ have also used $20 \%$ or $25 \%$ as the cutoff level for "good" knowledge and found that $25 \%-47 \%$ of physicians estimate costs within this range. Apart from the population sampled (emergency physicians), the methods and results of this study are directly comparable to previous studies.

\section{Limitations}

This study addresses only cost awareness; it does not demonstrate inappropriate utilization, nor prove the opportunity for cost reduction. Because this survey was performed in a geographically circumscribed urban setting, it is unclear whether the conclusions can be generalized to other regions of the country.

The appearance of octreotide (a drug rarely prescribed by EPs) on the study's top 20 list reflects a problem EDs are increasingly forced to deal with. With the lack of inpatient beds, many patients languish in the ED long after admis-

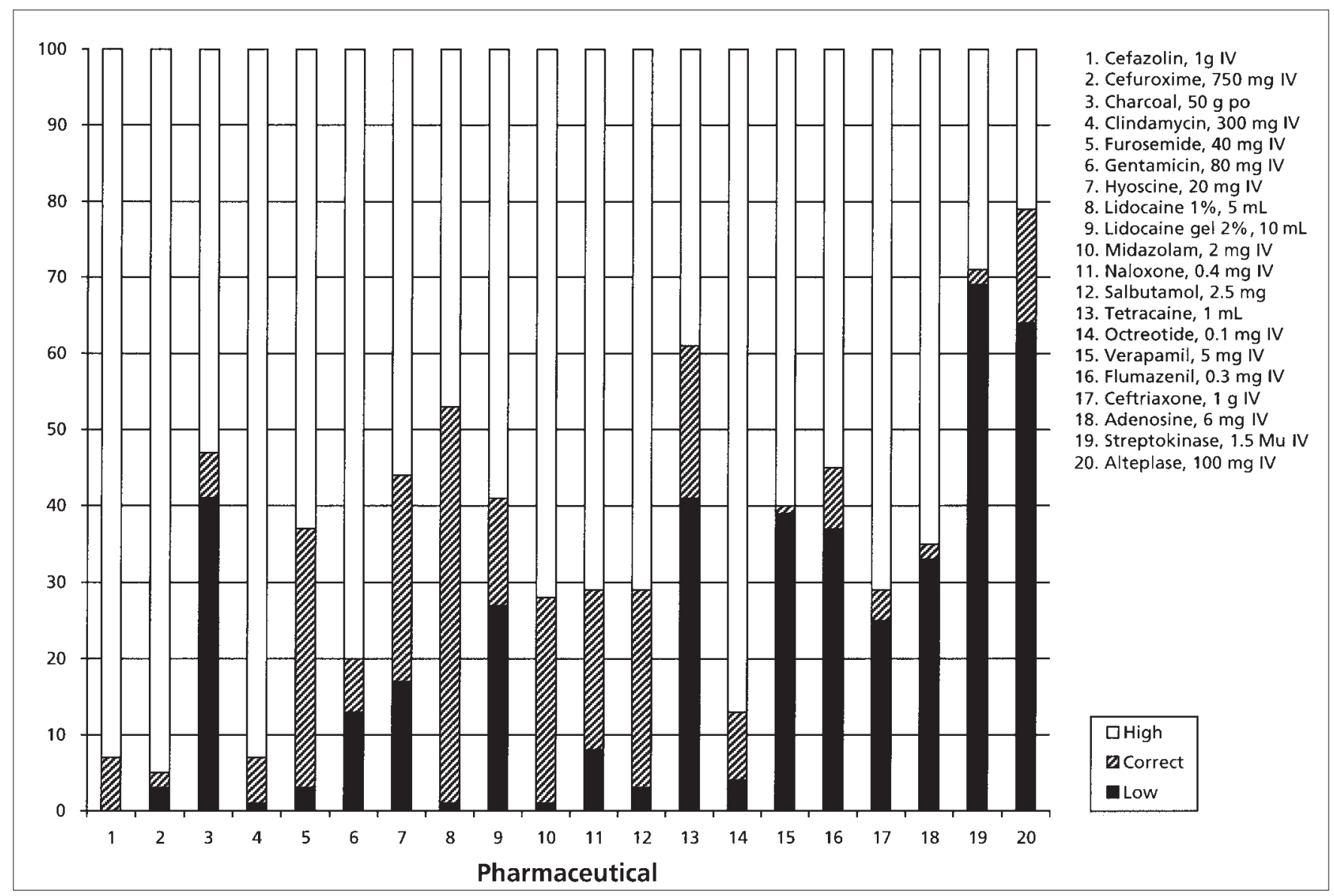

Fig. 3. Proportion of low, correct and high estimates for pharmaceuticals, \%. 
sion. In the study hospitals, because of poor information systems that do not link utilization to the responsible physician, tests and interventions (e.g., octreotide) ordered while patients remain physically in the ED are automatically and incorrectly attributed to the EP. Clearly EPs should not be expected to have cost awareness for agents they do not use.

\section{Conclusions}

Emergency physicians have limited knowledge of common medical care costs. They overestimate pharmaceutical and laboratory costs and underestimate diagnostic imaging costs. Cost-awareness programs for EPs are most likely to be effective if they focus on imaging modalities, particularly plain film x-rays.

\section{References}

1. Beveridge RC. Emergency medicine: a Canadian perspective. Ann Emerg Med 1995;26:504-7.

2. Statistics Canada. Hospital indicators 1989-90. Part 2: Diagnostic and therapeutic. Ottawa: Statistics Canada; 1993. p. 10-1.

3. Canadian Institute for Health Information. Total health expenditures: Summary/Canada, 1975-1997 (database). Ottawa: The Institute, 1998.

4. Andrus LH. The emergency room rip-off. J Fam Pract 1975; 2:147-8.

5. Burnett MG, Grover SA. Use of the emergency department for nonurgent care during regular business hours. CMAJ 1996; 154:1345-51.

6. Wehmer R. Let's put a stop to emergency room abuse. Tex Med 1992;88:9-10.

7. Fortier ME. Health care funding update. Canadian Medical Association Conference on regionalization and decentralization of health care. Kingston, Ont.; June 1995.

8. Kelly L, Birtwhistle R. Is the problem urgent? Can Fam Physician 1993;39:1345-52.

9. Gill JM. Nonurgent use of the emergency department: Appropriate or not? Ann Emerg Med 1994;24:953-7.

10. Williams RM. The costs of visits to the emergency department. N Engl J Med 1996;334:642-6.

11. Williams RM. Distribution of emergency department costs. Ann Emerg Med 1996;28:671-6.

12. Stiell IG. The "real" Ottawa Ankle Rules. Ann Emerg Med 1996;27:103-4.

13. Anis AH, Stiell IG, Stewart DG, Laupacis A. Cost-effectiveness analysis of the Ottawa Ankle Rules. Ann Emerg Med 1995; 26:422-7.

14. Grossman RM. A review of physician cost-containment strategies for laboratory testing. Med Care 1983;21(8):783-802.

15. Tierney WM, Miller ME, McDonald CJ. The effect on test ordering of informing physicians of the charges for outpatient diagnostic tests. N Engl J Med 1990;322:1499-504.

16. Cummings MK, Frisof KB, Long MJ, Hrynkiewich G. The effect of price information on physicians' test ordering behaviour. Med Care 1982;20:271-3.

17. Eisenberg JM. An educational program to modify laboratory use by house staff. J Med Educ 1977;52:578-81.

18. Schroeder SA, Kenders K, Cooper J, Piemme T. Use of laboratory tests and pharmaceuticals - variation among physicians and the effect of a cost audit on subsequent use. JAMA 1973;225:969-73.

19. Henderson D, D'Alessandri R, Westfall B, Moore R, Smith R, Scobbo R, et al. Hospital cost containment: a little knowledge helps. Clin Res 1979;27:279A.

20. Cohen DI, Lones P, Littenberg B, Neuhauser D. Does cost information reduce physician test usage? A randomized clinical trial with unexpected findings. Med Care 1982;20:286-92.

21. Karas S. Cost-containment in emergency medicine. JAMA 1980; 243:1356-9.

22. Long MJ, Cummings KM, Frisof KB. The role of perceived price in physicians' demand for diagnostic tests. Med Care 1983; 21:243-50.

23. Kelly SP. Physicians' knowledge of hospital costs. J Fam Pract 1978;6:171-2.

24. Pennycook A. Are blood tests of value in the primary assessment and resuscitation of patients in the A \& E department? Post Med J 1995;71:71-5.

25. Sandler G. Do emergency tests help in the management of acute medical admissions? Br Med J 1984;289(Suppl 13):973-7.

26. Thomas DR, Davis KM. Physician awareness of cost under prospective reimbursement systems. Med Care 1987;25:181-4.

27. Petty C. Cost awareness is needed for cost-containment. AANA J 1988;56:188-9.

28. Robertson WO. Costs of tests: estimates by health professionals. Med Care 1980;18:556-9.

29. Skipper JK, Smith G, Mulligan JL, Garg ML. Physicians' knowledge of cost: the case of diagnostic tests. Inquiry 1976;13:194-8.

30. Fowkes FGR. Doctors' knowledge of the costs of medical care. Med Educ 1985;19:113-7.

31. Lyman JL, McCabe JB. Emergency department care: cost awareness by health care providers. J Emerg Med 1987;5:567-71.

32. Hart J, Salman H, Bergman M, Neuman V, Rudniki C, Gilenberg D, et al. J Int Med 1997;241:415-20.

33. van de Val BW. Expenditure on medicine at provincial hospitals in the Cape. A comparative analysis from 1982-1989. S Afr Med J 1991;80:553-7.

34. Frazier LM, Brown JT, Divine GW, Fleming GR, Philips NM, Siegal WC, et al. Can physician education lower the cost of prescription drugs? Ann Int Med 1991;115:116-21.

35. Glickman L, Bruce EA, Caro FG, Avorn J. Physicians knowledge of drug costs for the elderly. J Am Geriatr Soc 1994;42:992-6.

36. Nagurney JT, Braham RL, Reader CG. Physician awareness of economic factors in clinical decision making. Med Care 1979; 17:727-30.

37. Dresnick SJ, Roth WI, Linn BS, Pratt TC, Blum A. The physicians role in the cost containment problem. JAMA 1979;241:1606-9.

Correspondence to: ginnes@interchange.ubc.ca 